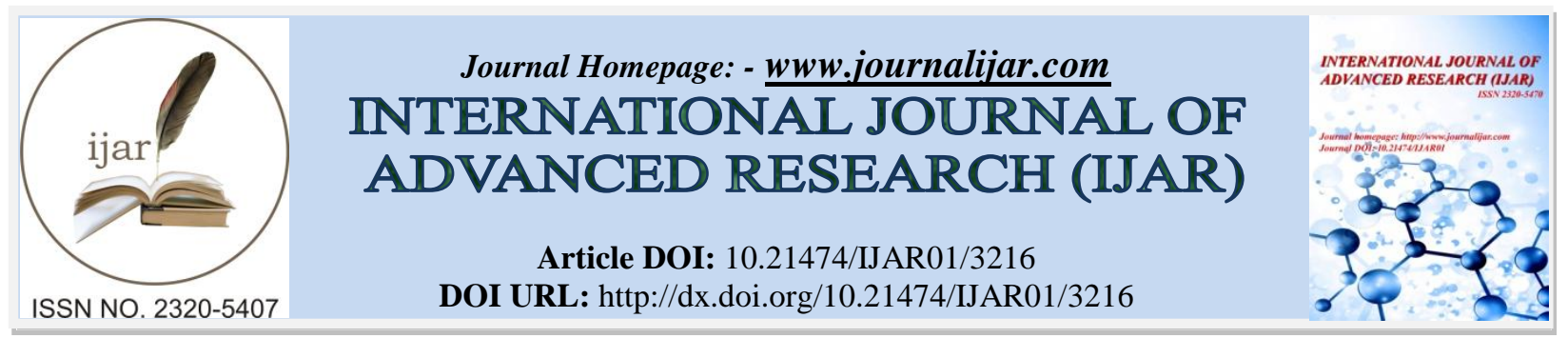

RESEARCH ARTICLE

\title{
SINGLE CRYSTAL GROWTH AND CHARACTERIZATION OF ZINC DOPED MAGNESIUM THIOUREA ACETATE CRYSTALS.
}

\author{
V. Rajendran and S.Sangeetha* \\ PG \& Research Department of Physics, Presidency College, Chennai 600005, India.
}

\section{Manuscript Info}

Manuscript History

Received: 09 December 2016

Final Accepted: 14 January 2017

Published: February 2017

Key words:-

Solution growth, Single crystal XRD,

Optical material, Thermal studies, NLO material

\begin{abstract}
A semi organic nonlinear optical single crystals of zinc magnesium thiourea acetate (ZMTA) were grown from slow evaporation technique at room temperature. The unit cell parameters were determined from single crystal X-ray diffraction studies. FTIR studies were performed to identify the functional groups present in the compound. The UV-Vis spectrum indicates the grown crystal has good transparency in the entire UV-Vis region spectrum suggesting the suitability of the material for NLO applications. The thermal studies show that the crystal is thermally stable up to $120^{\circ} \mathrm{C}$. The relative second harmonic efficiency of the compound is found to be 1.64 times greater than that of KDP.
\end{abstract}

Copy Right, IJAR, 2017,. All rights reserved.

\begin{abstract}
Introduction:-
In recent development of research in nonlinear optical phenomena are involved in scientific and industrial applications. The property of second harmonic generation are focused in electro optic modulation, optical switching and also it involves in the domain of optoelectronic and photonics. Especially organic and inorganic materials are given increasing attention due to its rapid technological advances in various fields, such as laser technology, fibre optics, telecommunication, optical computing and optical data storage technology [1-3]. To overcome the limitation of these materials, interests have been focused on semi-organic crystals. In which it leads to explore the combined properties of both inorganic and inorganic crystals like high damage threshold, wide transparency range, less deliquescence, higher mechanical strength and thermal stabilities are obtained for device fabrication $[4,5]$. Recently effort has been made on metal complexes of thiourea and analogues. Inorganic matrix of thiourea molecules are an interesting material plays important role due to their large dipole moment and ability to form an extensive network of hydrogen bonds with metals [6,7]. The NLO properties of some complexes of thiourea, such as bis (thiourea) cadmium sulphate (CTS) [8], potassium thiourea bromide (PTB) [9] and zinc thiourea sulphate (ZTS) have been reported elsewhere [10]. In the present investigation, the effect of Zinc doped MTA crystals have been studied using single crystal XRD, FT-IR, UV-Vis, thermal and microhardness of the grown crystals have been carried out. The NLO property of as grown crystal has been confirmed by Kurtz powder technique.
\end{abstract}

\section{Synthesis and crystal growth:-}

Single crystal of zinc doped MTA material was synthesized using AR grade of Thiourea, Magnesium acetate and Zinc acetate. Double distilled water was used as a solvent. Calculated amount of (3: 0.9: 0.1) the above materials were dissolved in $100 \mathrm{ml}$ of water and stirred well using magnetic stirrer. Well defined single crystals of good transparency were harvested after a period of 15 days and shown in Fig.1. 


\section{Result and Discussion:-}

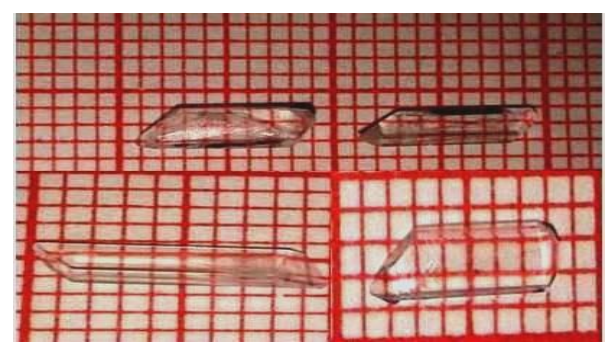

Fig 1:- Photograph of ZMTA crystals

\section{Single crystal XRD studies:-}

The grown crystals were analyzed by single crystal X-ray diffraction to confirm the crystallinity and also to estimate the lattice parameters. From the single crystal X-ray diffraction data, it is observed that the ZMTA crystal is Monoclinic in structure. The morphology of the grown crystal seems to be different when compared with Zinc magnesium tris thiourea sulphate (ZMTS) and Magnesium doped tris thiourea zinc sulphate (TTMZS) [11, 12]. The calculated unit cell parameters are given below in Table 1 and there values are compared with the reported values.

Table 1:- Unit cell parameters of grown and reference crystals

\begin{tabular}{|cccccc|}
\hline Crystal systems & $\mathrm{a}(\AA)$ & $\mathrm{b}(\AA)$ & $\mathrm{c}(\AA)$ & Volume $\left(\AA^{3}\right)$ & Crystal structure \\
\hline ZMTA & 7.113 & 17.694 & 11.111 & 1363.9 & Monoclinic \\
ZMTS & 7.74 & 11.08 & 15.42 & 1337 & Orthorhombic \\
TTMZS & 15.57 & 6.315 & 5.549 & 545.4 & Orthorhombic \\
\hline
\end{tabular}

Changes in the lattice parameters may be due to incorporation of dopant which causes the increase in volume. However, for ZMTA crystal, changes in the lattice parameters have been observed with respect to ZTMS and TTMZS crystals which confirm that the doped crystal exhibits different structure as that of parent material.

\section{Optical absorption studies:-}

An optical absorption spectrum of ZMTA crystals were recorded in the wavelength range 200-800 nm using PerkinElmer Lambda $650 \mathrm{UV}$-Vis spectrometer and is shown in Fig. 2. The UV spectrum shows a wide transparency window with the lower cut off wavelength of grown crystal is $235 \mathrm{~nm}$. Absence of absorption in the region between $260-800 \mathrm{~nm}$ is the essential property for the NLO material. The less absorbance behavior in the entire visible region also confirms the colorless nature of the crystal.

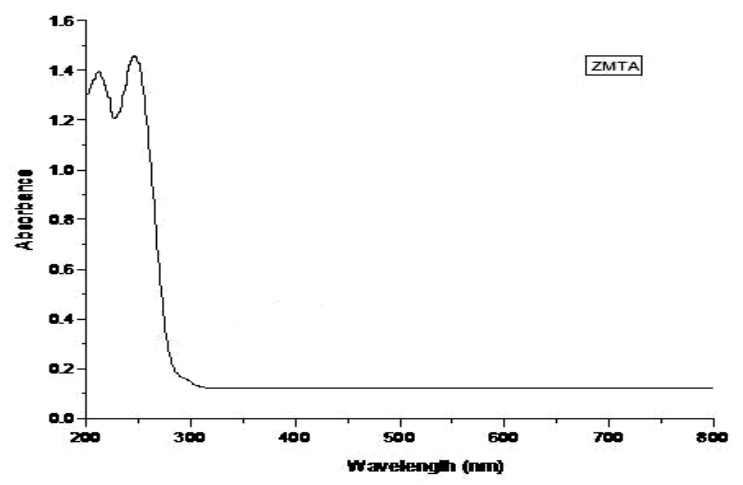

Fig 2:- UV-vis absorption spectrum of ZMTA crystal.

It is observed that the grown crystal has good transparency in the UV-Visible and IR region. While doping Zinc acetate with MTA crystal alter the lower cut off wavelength increase when compared to the reported values [11, 12]. 


\section{FTIR studies:-}

The FTIR spectrum of ZMTA crystal displayed in Fig.3 were recorded in the range of $400-4000 \mathrm{~cm}^{-1}$. The vibrations at 3378 and $3304 \mathrm{~cm}^{-1}$ are reported as vibrations due to $\mathrm{NH}_{2}$ asymmetric stretching vibrations and the $\mathrm{C}-\mathrm{H}$ stretching vibration is observed at $2349 \mathrm{~cm}^{-1}$. The peak at $1635 \mathrm{~cm}^{-1}$ is due to $\mathrm{N}-\mathrm{H}$ bending vibration [13]. The $\mathrm{C}=\mathrm{O}$ stretching vibration is observed at $1571 \mathrm{~cm}^{-1}$. The peak at $1389 \mathrm{~cm}^{-1}$ is reported as vibration due to $\mathrm{C}=\mathrm{S}$ asymmetric stretching vibration [14]. The $\mathrm{NH}_{2}$ rocking vibration is observed at $1131 \mathrm{~cm}^{-1}$ [11]. The absorptions at 931 and $475 \mathrm{~cm}^{-1}$ are reported as the vibrations due to $\mathrm{N}-\mathrm{C}-\mathrm{N}$ symmetric stretching vibrations $[11,12]$. The vibrations around 600 and $1030 \mathrm{~cm}^{-1}$ are reported as clear conformation of presence of zinc acetate in the coordination sphere [15]. Based on the observations, it is confirmed that FTIR spectra indirectly establish the presence of zinc acetate in lattice of MTA crystal.

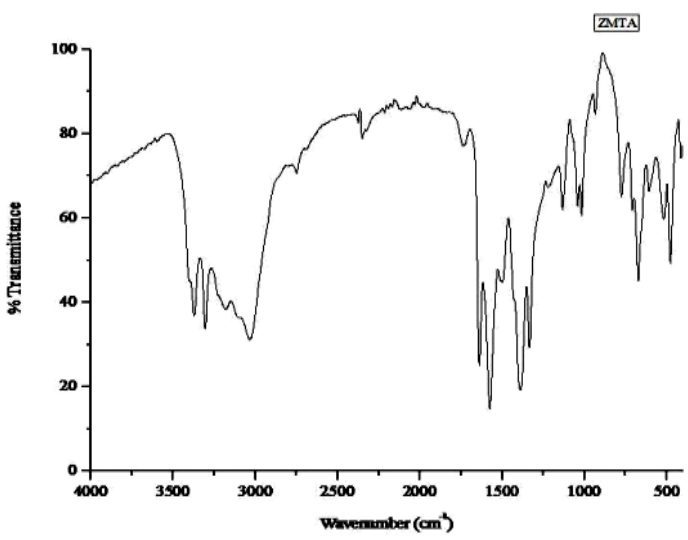

Fig 3:- FTIR spectrum of ZMTA crystal.

TG/DTA studies:-

TG/DTA curves of ZMTA crystal displayed in Fig.4. From the result, the crystal is thermally s0table up to $120^{\circ} \mathrm{C}$ and it is observed that DTA curve show endothermic peak at $210{ }^{\circ} \mathrm{C}$ for ZMTA crystal. This value can be considered as the decomposition or melting point of the sample. From the result, it is noticed that ZMTA crystal has slightly less thermal stability than reported value of ZMTS crystal and it may due to decrease in bond energy caused by the incorporation of dopant's anion $\left(\mathrm{CH}_{3} \mathrm{COO}\right)_{2}{ }^{-}$in the lattice of the ZMTA crystal. The TG curve of ZMTA crystal show maximum weight loss occurs in the temperature range $120-348^{\circ} \mathrm{C}$, which is due to the decomposition of the samples. The sharpness of the endothermic peak shows the good degree of crystallinity and purity of the sample. Further the absence of water in the molecular structure is confirmed by the absence of weight loss around $100^{\circ} \mathrm{C}$.

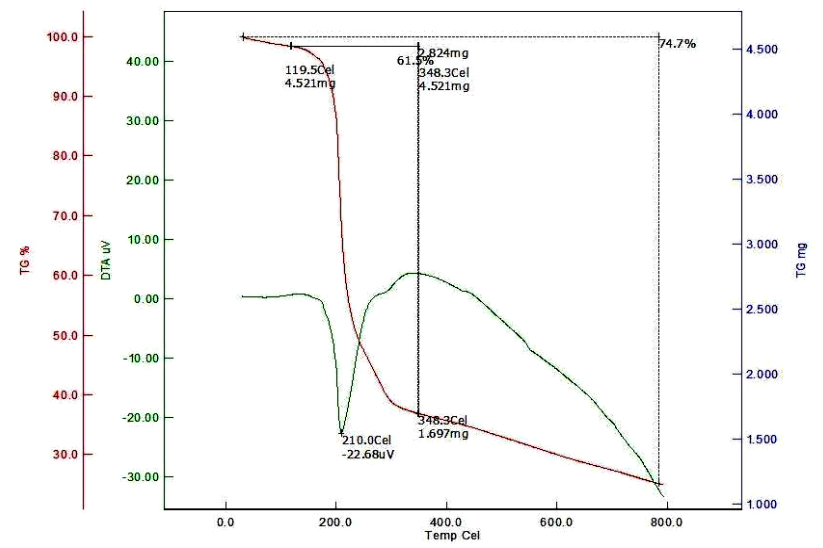

Fig 4:- TGA-DTA curves of ZMTA crystal.

\section{Powder SHG Studies:-}

The second harmonic generation efficiency of grown crystal has been measured by Kurtz-Perry technique [16]. A Q- switched mode- locked Nd: YAG laser was used to generate about $0.68 \mathrm{~mJ} / \mathrm{pulse}$ at $1064 \mathrm{~nm}$ fundamental radiation. The second harmonic signal was confirmed from the emission of green radiation by the crystalline powder 
sample. The result of SHG efficiency of the grown crystal is about $14.42 \mathrm{mV}$. KDP crystal was used as reference material in the SHG measurement. The ZMTA gives an SHG of $14.42 \mathrm{mV}$, while the KDP gave an SHG signal of $8.8 \mathrm{mV}$ for the same input beam energy. The SHG relative efficiency of ZMTA crystal was found to be 1.64 times higher than that of KDP.

\section{Conclusions:-}

Optically good quality ZMTA crystals were grown by slow evaporation technique. The presence of small amount of zinc acetate altered the unit cell parameters slightly when compared to reported value. The presence of functional groups was determined by FTIR analysis. The optical absorption studies show that the UV cut-off wavelength of grown crystal is $245 \mathrm{~nm}$ making it a suitable candidate for NLO applications. The TG/DTA studies show that the grown crystal is thermally stable up to $120^{\circ} \mathrm{C}$. The SHG efficiency of ZMTA crystal is 1.64 times higher than that of KDP and it becomes a promising candidate for optoelectronic and photonic device applications.

\section{References:-}

1. J. Erwan, A.Nathalie, D. Xerox, J. Mater. Chem. 12 (2002) 2383-2389.

2. X.Q. Wang, D. Xu, X.F. Cheng, M.K. Lu, D.R. Yuan, Phys. Status Solidi A 198 (2003) 43 - 48.

3. D. Wang, G. Zhou, X. Xu, H. Liu, Y. Ren, Z. Shao, M. Jiang, Opt. Laser Technol. 34 (2002) 343-346.

4. P. R. Newman, L.F. Warren, P. Cunningham, T.Y. Chang, D.E. Cooper, G.L. Burdge. Et al., Mater. Res. Soc. Symp. Proc. 173 (1990) 557-561.

5. U. Ramabadran, D.E. Zelmon, G.C. Kennedy, Appl. Phys. Lett. 60 (1992) 2589-2591.

6. T. C. Sabari Girisun, S. Dhanuskodi, Chem. Phys. Lett. 491(2010) 248-253.

7. Hellwege, K.H.,Hellwage, A.M.Landott - Bornstein Group II 14 (1982) 584.

8. M. Oussaid, P. Becker, M. Kemiche, C. Carabatosnedelec, Phys. Status solidi B 207 (1998) 103.

9. G. Xing, M. Jiang, Z. Shao, D. Xu, Chin. J. Lasers 14 (1987) 357.

10. RamaRamabadron, U.B., Mcpherson, A.L. Zelmon, D.E. J. Appl. Phys. 76 (1994) 1150.

11. A. Darlin Mary , K. Jayakumari , C.K. Mahadevan, Int. Journal of Engineering Research and Applications Vol.3, 2013, pp.1183-1197.

12. Bhuvaneswari Arvind, R.Dhanasekaran, International Journal of Science and Engineering Applications, pp. 7578.

13. A.Albert Irudayaraj, A. Dhayal Raj, G. Illavarasi, Growth and characterization of BTCS and BTZA crystals, Optik 125 (2014) 824-827.

14. K. Kanagasabapathy, R. Rajasekaran, Growth aspects, spectral, thermal and hardness studies of rare earth cerium (III) nitrate doped zinc (tris) thiourea sulphate single crystals, Optik 124 (2013) 4240-4245.

15. Le Fur Y. Masse R., Cherkaoui M.Z., Nicoud J.F., Z. Kristallogr. 210 (1995) 856.

16. S. K. Kurtz, T.T. Perry, J. Appl. Phys. 39 (1968) 3798-3813. 